Article

\title{
Assessing the Rationality and Walkability of Campus Layouts
}

\author{
Zhehao Zhang ${ }^{1}$, Thomas Fisher ${ }^{2, *}$ and Gang Feng ${ }^{1, *} \mathbb{D}$ \\ 1 School of Architecture, Tianjin University, Tianjin 300072, China; zhan7317@umn.edu \\ 2 School of Architecture, College of Design, University of Minnesota, Minneapolis, MN 55455, USA \\ * Correspondence: tfisher@umn.edu (T.F.); fenggangarch@tju.edu.cn (G.F.)
}

Received: 2 November 2020; Accepted: 1 December 2020; Published: 3 December 2020

check for updates

\begin{abstract}
Walking has become an indispensable and sustainable way of travel for college students in their daily lives and improving the walkability of the college campus will increase the convenience of student life. This paper develops a new campus walkability assessment tool, which optimizes the Walk Score method based on the frequency, variety, and distance of students' walking to and from public facilities. The campus Walk Score is the product of four components. A preliminary score is calculated through 13 types of facility weight and 3 types of cure of time-decay, and the final score also factors in intersection density and block length. We examine the old and new campuses of Tianjin University to test the tool's application and evaluate the rationality of facility layout and walkability, and to give suggestions for improvement. The results show that the old campus' multi-center layout has a high degree of walkability, while the centralized layout of the new campus results in lower walkability. In addition, the diversified distribution of facilities surrounding the old campus promotes the walkability of peripheral places. This assessment tool can help urban planners and campus designers make decisions about how to adjust the facility layout of existing campuses in different regions or to evaluate the campus schemes based on the results of their walkability assessment.
\end{abstract}

Keywords: Walk Score; walkability; public service facility; campus planning

\section{Introduction}

Walking, as a sustainable way of travel, plays a significant role in promoting the economy, the environment, and human health, which also has important social benefits [1-3]. As an important factor affecting the built environment, walkability has been widely used in the domains of health and physical activity, planning, transport, and urban design. Walkability can be broadly understood as the degree to which a particular environment induces walking activities and pedestrian friendliness, while measuring the space proximity, walking convenience, and comfort between the destination and the starting point. Because of the diversity of evaluation factors and different built environments, it can be difficult to define the concept of walkability [4]. Consequently, the current research on walkability mainly includes two directions.

One direction accepts the multi-dimensional definition of the term "walkability" by combining the environmental and social factors that induce walking, as well as the pedestrian's own attributes. For example, many scholars have focused on neighborhood walkability, defined as the capacity to support physical activity, including the access to different destinations, city block size, street connectivity, residential density, aesthetics, sidewalk access, and other community features [5-7]. Some scholars have also given more comprehensive definitions combining pedestrian's walking preference, safety, comfort, and friendliness for walking with built environment characteristics and the means, outcomes, and influences related to a walkable environment $[8,9]$. 
The other direction uses qualitative analysis and quantitative empirical research to measure walkability using field audit methods and to explore walking's association with health, the environment, economics, social capital, and other subjects [10-12]. The methods to measure walkability can be divided into a subjective evaluation of the walking environment based on questionnaires, an objective evaluation system based on field audits, and an integrated method combining subjective and objective measures, as well as a proposed walkability index method integrating various environmental characteristics (i.e., land use mix, residential density, street connectivity) [12].

As a powerful method of assessing walkability, using a GIS algorithm, Walk Score has become a valid and reliable proxy to evaluate access to nearby facilities such as coffee shops, restaurants, grocery stores, drug stores, schools, and bars [5,6]. It avoids the shortcomings of time-consuming and laborious field observation and inaccurate subjective evaluation data. Due to its accessibility, global scope, and the objectivity of its measurement, Walk Score is increasingly recognized as an important international quantitative measurement method [1]. In addition, it takes the number and the types of facilities as well as their layout pattern into consideration. Walk Score also looks at the time and distance it takes to walk to destinations, the population density, and the street length and intersection density to adjust the value. Using a standardized scale from $0-100$, with higher values indicating a more walkable environment, Walk Score divides that scale into five intervals: 0-24 car-dependent, 50-69 somewhat walkable, 70-89 very walkable, and 90-100 walker's paradise (Walk Score ${ }^{\circledR} 2011$ ).

Users can easily search and get dynamic visual outcomes by inputting the address of locations on the Walk Score platform. However, other studies focus on the impact on travel behavior of facility layout and distribution, mainly in terms of accessibility and spatial equity [13,14]. Many GIS-based methods (i.e., network analysis, distance-based, gravity-based or potential, topological or infrastructure-based methods) are widely used to study the spatial accessibility of a single facility or multiple facilities [15]. For example, Kyushik Oh proposed the concept of a service index, using the network analysis function of GIS to analyze park accessibility in Seoul, Korea [16]. Another research study applied a method called integrated spatial equity evaluation (ISEE) to study the spatial equity of various urban-service facilities in Tehran, Iran, as a way to verify the ISEE method [13].

Although different from the above methods, Walk Score takes the block length and the intersection density into account and calculates the shortest distance from the starting point to various service facilities based on the actual road network distance. Research on the application of Walk Score has mostly concentrated on North America and Australia, and mostly focused on adults. Only a few articles have studied other regions (Asia) and special groups (the elderly, women, and the disabled) [4]. Additionally, Cubukcu et al. stated that the research on the application of various quantitative walkability methods is mostly concentrated in developed countries, and Asia should not be undertested as the verification and application of current research methods [17]. Meanwhile, the literature on Walk Score mostly focuses on the neighborhood, community, district, and city scale, and to date, campus walkability has not been measured using the Walk Score method. At the same time, the facility weight in the Walk Score calculation does not make a detailed classification of users, and the differences of the curve of time-decay (one of the factors affect the Walk Score calculation) between different groups of people who go to different facilities are not taken into account. Finally, the walking demand of campus students has not been considered in the study of Walk Score.

As a part of the city, university campuses play an important role in enriching urban life, creating a sustainable built environment, and promoting economic development and environmental protection. Different from primary and middle schools, university campuses have certain similarities with cities because of their mix of functions, large scale, and population diversity, even though their special spatial pattern, land use, and functional form are significantly different from other areas of the city (residential, commercial, and industrial). As Salingaros wrote, "a college or university campus represents an urban microcosm, with its limited yet often extensive area and restricted mixture of uses; the pedestrian realm is paramount, since students have to walk from building to building" [18]. Therefore, it is very important to study the spatial quality and the walking environment of the campus. The research on the 
walkability of university campuses is mostly based on the combination of various existing field-audit methods and the empirical verification and comparative study of a single campus or multiple campuses based on that evaluation system [19-21]. The research on campus walkability based on the distribution of public service facilities is rarely involved.

There are two main knowledge gaps. 1. As a useful measurement walkability tool in real estate, public health, and urban neighborhood environment, the Walk Score method has not been applied to campus settings to evaluate the campus walkability from a macro-perspective. 2 . The process of campus planning and decision making has also not used the Walk Score method to evaluate, investigate, and adjust the distribution of facilities in existing or new campus plans to improve walkability and sustainability. To fill these gaps and as a complement to the existing research, this paper proposes an evaluation tool for measuring campus walkability based on an optimized Walk Score method.

This tool combines the specific Chinese campus features, intersection density, block length, actual needs of students for the use and use frequency of campus facilities, as well as students' comfort time, tolerance time, and resistance time to arrive at various kinds of facilities. We present novel methods to establish 13 types of campus facilities and the facility weight, which considers the requirement of each facility through the data of students' weekly use frequency of each type of facility. Moreover, instead of mechanically following the original Walk Score method which uses the single cure of time-decay, we establish three types of curve of time-decay based on students' actual walking to different facility. Additionally, for the intersection density and block length, which will reduce the raw score from the facility weight and walking time, we also adjust the buffer distance to calculate these two components around each origin according to the difference of the campus scale and city scale. Further, we apply the measurement system to two campuses in Tianjin University, China (the old campus and the new campus) to test whether this tool is valid when evaluating and comparing campus walkability as well as diagnosing reasons for an area's low Walk Score. Additionally, we aim to analyze the impact of the layout of university facilities on the walkability of campuses and identify the association between Walk Score and the geographic location of a building on a campus.

This paper is organized as follows. Firstly, we review the research literature, aiming to define and measure walkability and to identify studies associated with the Walk Score method as well as campus walkability studies. Secondly, through the questionnaire survey, we collect the pertinent data about the students' use of university facilities and present the evaluation tool of an optimized Walk Score to measure campus walkability. Then, we use this tool to measure the walkability of two Chinese campuses from the aspects of the overall Walk Score and classified facilities' Walk Score. Moreover, the paper presents further reasonable layout suggestions, calculating the Walk Score of the new campus to assess and improve the walkability of the whole campus. Finally, this paper discusses the value of this tool in urban planning, policy-making, and campus planning, and points out the limitations of this study and the future research direction.

\section{Literature Review}

\subsection{Characteristics Affecting Walkability and Measuring Walkability}

Many studies have shown that a good pedestrian-friendly environment can bring several benefits such as strengthening social interaction or cohesiveness, improving individual health and environmental health, as well as economic development $[22,23]$. Built environment characteristics play a vital role in affecting pedestrian-oriented environment and improving walkability, and the configuration of urban areas can influence pedestrians' walking trips [24,25]. Different scholars have presented different numbers of built environment characteristics affecting environment walkability. Forsyth presented more than 200 variables impacting walkability, including aspects of street pattern, pedestrian-oriented design elements, and destinations, and she found that different walking purposes have different associations with an environment's physical characteristics [26]. Moreover, Lee and Moudon used theoretical and empirical approaches to select 13 VIP (variables have strong theoretical support) and 
19 non-VIP built environment variables to analyze the associations between physical-environment features and the probability of walking [27].

Additionally, some scholars focus on a specific characteristic and analyze its effect on walkability [28,29]. Boeing focused on the effect of circuity on travel and human choice for settlement. His findings show that the circuity of drivable networks is higher than that of walkable networks and, compared with straight-line distances, network-based distances play an important role in studying urban travel and access [28]. Ahmadpoor et al. studied the effect of environment legibility on people's navigation experience when they use digital-map devices and found that digital maps can produce poor recognition memory of the road they followed and the properties of the environment they encountered compared with the direct experience [29]. Meanwhile, Ahmadpoor and Shahab studied the development of spatial knowledge theories and analyzed the important role of spatial knowledge in how people perceive and interact with the surrounding environment. They further explored how spatial knowledge acquisition (direct experience, physical map, and mobile maps) in the physical environment affected spatial knowledge [30]. Moreover, Gao et al. studied the urban morphology of Chinese urban villages and analyzed the effects of formal city planning on these settlements' development. The researchers examined the morphology of an area of Dayuan Village in Guangzhou in terms of its urban density, accessibility, functional mix, and urban interface. They also studied the relationships among these four elements, and they found that different types of streets have a considerable impact on different elements. Their framework can be used to analyze the urban morphology characteristics of other Chinese urban villages [31].

Generally, walkability can be conceived in the following aspects: accessibility to destinations, street-connectivity, pedestrian amenities, aesthetics, residential density, land use mix, and safety [32-34]. Based on these characteristics, many scholars have put forward different walkability metrics, such as Pedestrian Environment Index, Walkability Index, Walking Access Index, Walk Opportunities Index, Walk Score, etc. [12,23,35-42]. These indices mainly refer to residential density [12,23,35,38,39,42], intersection density [12,23,35,38,39], land use mix [12,23], and distances to different destinations [37]. Frank et al. presented a walkability index combining residential density, intersection density, and land-use mix, and subsequently added retail floor area ratio into the equation. They also presented another Walkability Index and use this new index to analyze the effect of walkability on adults' physical activity [12,35]. Accordingly, Glazier combined population density, residential dwelling density, street connectivity, and retail outlets density to present another walkability index for Canadian settings [38]. Similar to the metrics discussed above, Peiravian et al. combined four sub-indices (land use density index, population density index, commercial density index, and intersection density index) to put forward a Pedestrian-friendly Index, multiplying each component index instead of directly summing them, which avoids influences between components [23]. Additionally, for the effect of travel distance and walking time on walkability, Saghapour presented a Walking Access Index (WAI) based on the combination of points of interest (POI) density and two types of walking time (desirable and maximum travel time) and found that WAI has a stronger relationship with recorded walking trips [37]. Although these indices have taken into account different aspects of built-environment characteristics, these methodologies seldom consider the effect of facilities' layouts on the levels of walkability.

\subsection{Walk Score}

As an international walkability measurement metric based on the combination of facility layout, street connectivity, and block length, Walk Score has led many scholars to make in-depth explorations of it, looking at aspects of the living environment, urban design features and qualities, walkability, affordability, physical activity, and walking behavior [43-46]. The validity of Walk Score as a standardized method to measure walkability has also been examined [41-43]. Duncan et al. used GIS to verify the reliability of utilizing Walk Score to measure neighborhood walkability both in multiple geographic locations and at multiple special scales [43]. Walk Score also correlates well with actual walking behavior. A study of 391 U.S. immigrants from Cuba conducted by Brown et al. found that 
every 10-point increase in Walk Score will increase "purpose walking" by 19\% [44]. Koschinsky and Talen investigated the relationship between walkability and affordability and discussed neighborhood factors that may affect these two features [46]. Many scholars have also optimized Walk Score, combining population density, walk share, and trip type as well as different scales of intersection density and block scale. Weinberger used three optimized Walk Score models, based on walk share for different trip types, to analyze the correlation between Walk Score and walking [42].

Since the introduction of Walk Score in China in 2012, many Chinese scholars have also investigated

it. Based on differences in urban development stage, urban spatial environment, block scale, road network density, and residents' travel habits, scholars have optimized and improved the Walk Score evaluation system, and applied this method to the study of parks, neighborhoods, communities, and cities [47-51]. A study of the adjustment of Walk Score for the walkability of the elderly, conducted by Huang, $\mathrm{Hu}$, and $\mathrm{Li}$, recommended improving the Walk Score evaluation system from the perspective of the elderly, discussing the influence of three types of communities with different facility layout patterns on walkability in Shanghai [49]. Examining recreational places and parks, which are omitted in Walk Score, Wu and Shen used Walk Score to evaluate the social service function of urban parks and green space in Futian District, Shenzhen, and the results provide a basis for incorporating Walk Score into the construction and evaluation of urban parks and green space [50].

For the comparisons of walkability between different cities, Long et al. used a simplified Walk Score method to assess and compare the street walkability of various Chinese cities based on visualized outcomes. The results show that the Walk Score pattern is polarized, that the Walk Score of western and eastern Chinese cities is higher than that of northwestern and northern ones, and that the provincial-capital and sub-provincial cities are higher than prefecture-level cities and municipalities [52]. Furthermore, many scholars have studied the relationship between Walk Score and environmental and social factors such as street function, facility layout, green ratio, real estate, and other characteristics [51,53]. Long et al. analyzed the association between Chengdu streets' Walk Score with street function, distance to different destinations, and green ratio, and found that the Walk Score of the residential streets is the highest and the distance from the origin to the administrative center has an effect on the street walkability [51]. Another research study used the adjusted Walk Score method to measure the walkability of certain areas in Shenzhen, analyzing the association between Walk Score and population density, house price and other attributes, finding that Walk Score has a positive relationship with population density and house price [53].

Although Walk Score has been validated as a reliable macro-scale evaluation method to assess the walkability of urban areas, this metric still has limitations. The most striking is that Walk Score omits the subjective feelings of pedestrians about the walking environment [54]. Furthermore, Walk Score does not include micro-scale factors such as the quality of the street environment, the condition of the street amenities like the width of sidewalks, street lights, street furniture, and negative factors such as traffic and crime [55]. Importantly, this method has not been applied to the campus environment setting.

\subsection{Campus Walkability}

The research on the walkability of campuses can also be divided into two major directions. The first direction looks at the specific built environment of the campus, as scholars apply and optimize the existing methods of measuring the walkability of cities, communities or neighborhoods, and workplaces to present a new way to measure campus walkability [56,57]. Xiangyu Li et al. put forward a subjective and objective method, comprehensively evaluating the walkability and bike-ability of University of North Texas campus streets [57]. Using the subjective and objective method as well, King et al. pursued another approach, combining environmental characteristics, campus members' perceptions of walkability, and other characteristics related to physical activity to measure the campus walkability [56].

The second direction analyzes the correlation between the campus walkability and the subjective evaluation of walkability, the characteristics of built environment, students' physical activity and BMI, travel mode, social capital, and other factors [19-21,58-63]. In many studies, several factors are often 
mixed to explore their effects on walking behavior and walkability. For the subjective evaluation of campus walkability and built-environment characteristics, researchers have used audit tools (i.e., Systematic Pedestrian and Cycling Environmental Scan, Pedestrian Environment Data Scan, etc.) to conduct the research around the perceptions of the walkability, the assessment of the residential density, land-use mix, aesthetics, safety, and existing infrastructure such as sidewalks, walking paths and other factors, as well as the effects of these environmental features on walking behavior and walking activity intensity $[19,20,59]$. A study of the impact of on-campus and off-campus built environment characteristics on students' physical activity showed that a campus with land-use mix, aesthetics, and a lack of cul-de-sacs can promote students' physical activities [59].

A large number of studies have focused on the impact of campus walkability on students' physical activity, conducted not only from the objective differences of the built environment and students' subjective cognition of environment characteristics, but also in terms of the proximity to facilities and perceived safety [21,59-62]. Sisson et al. studied the walkability and students' physical activities of two campuses that have different built environments, and found that the walking intensity of students living on a campus that has core academic areas, with many on-campus destinations and limited parking lots, is higher than those living on a campus with low accessibility to destinations and streets open to motorized traffic [21]. Furthermore, for the relationship between campus walkability and travel-mode commuting, researchers have primarily focused on the influence of the destinations' spatial location on walkability and the extent of access to different destinations $[58,63]$. One research study found that students living in residential areas with dense service facilities and good walkability prefer to walk or ride to the campus [63]. Likewise, there are also significant differences in the research objectives of the studies of campus walkability, including the evaluation of a single campus, the comparisons between two or more campuses, and the on-campus and off-campus built environment of the same campus $[21,56,59]$.

Although many scholars have carried out qualitative and quantitative research on the effects of environmental and social characteristics on campus walkability, students' walking behavior, and physical activity, as well as the optimization of the audit methods adapted to the evaluation of the campus walkability, there is a lack of research on the influence of the layout and students' use of campus facilities on campus walkability, particularly when applying the Walk Score method.

\section{Materials and Methods}

\subsection{Study Area}

The old and new campuses of Tianjin University were selected for this research (Figure 1). The new campus is located in Jinnan District, which is in the suburban area of Tianjin. Inside the campus, public-service facilities are centralized along the east-west main axis, while the areas around the campus are farmland and vacant lots, with no facilities located along the streets around the campus. The old campus, located in the city center of Tianjin's Nankai district, has a facility pattern and architectural style formed after many years of planning and construction. Unlike the new campus, the internal facilities of the old campus are distributed in multiple centers. The old campus is also close to Nankai University to the south, and the city's main road, where a variety of facilities and services are located along the north and east side of the campus. In order to consider the particularity of the boundary and marginal zone of the area, this research expanded the scope of facilities selected by $1000 \mathrm{~m}$ from the original campus boundary.

\subsection{Data Sources}

Through a questionnaire and field interviews, 665 students in the new and old campuses of Tianjin University were surveyed, and 615 valid questionnaires (305 in the new campus and 310 in the old campus) were obtained (Table 1). All the participants are Chinese students living inside the campus. The questionnaire included online and offline forms, and each respondent clicked on the 
QR code link to complete a 10-min survey. It took two months (April and May in 2019) to collect the data simultaneously on both campuses. The questionnaire is divided into three parts. The first part involves the demographic variables, such as age, gender, major, grade, and apartment addresses of students; the second part investigates the condition of using public service facilities on campus, including the frequency of using different facilities (e.g., canteen, library, gym, retail store, etc.) every week and the preference of different facilities of the same type. Finally, the paper evaluates the walking comfort time, tolerance time, resistance time, campus overall walkability, and the satisfaction of the location of facilities. The data mainly involve two aspects: 1 . facility layout and 2 . street network.

1. Facility layout. This paper classifies facilities according to 13 common types, dispensing with some rarely used facilities (e.g., hospital, affiliated kindergarten of the university, etc.). The paper also locates the facilities through POI (points of interest) data from Google Maps and field observation to add newly constructed or eliminate unused facilities (Figure 2).

2. Street network. Dealing with road-network data collected in 2013, the paper also corrects it through the Cadmapper website and field observation to revise the problematic data to obtain an accurate outcome.
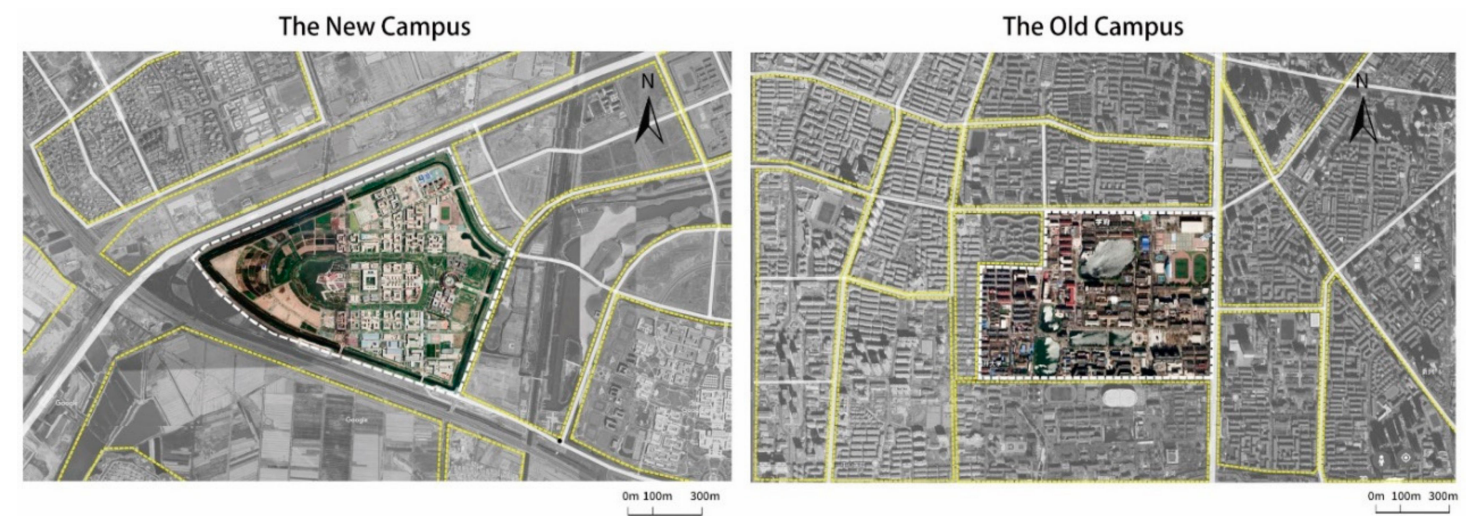

Figure 1. The geographic location and the boundary of the two campuses.
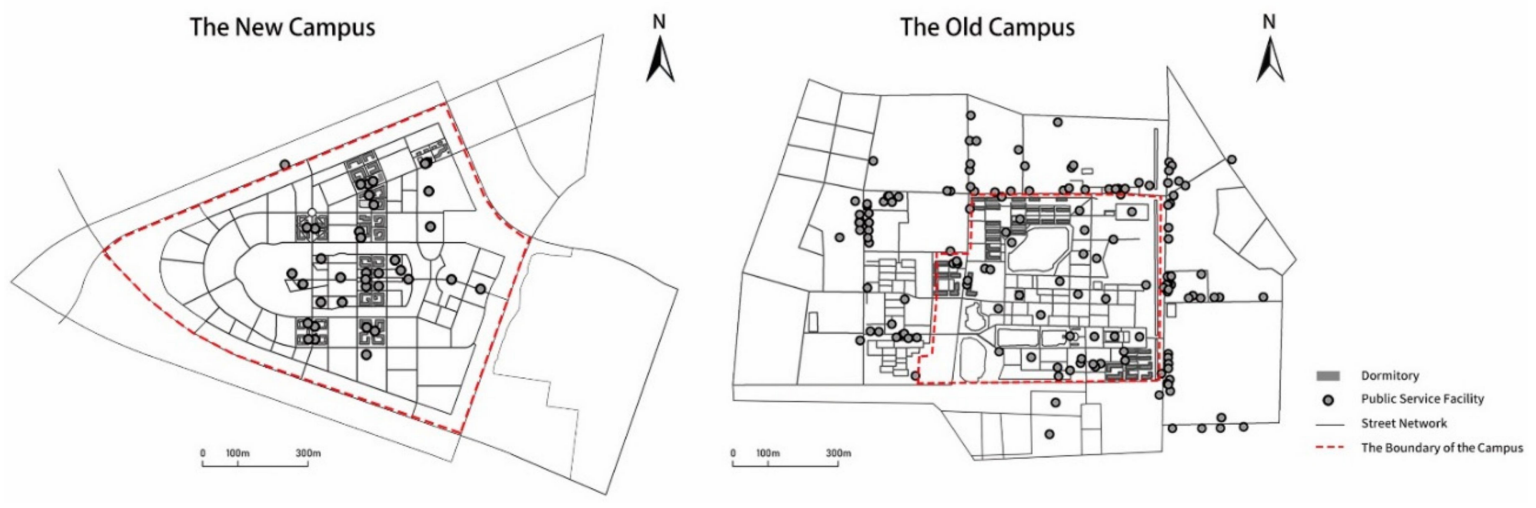

Figure 2. The layout of the public service facilities of the two campuses.

Table 1. Demographic data in the two campuses.

\begin{tabular}{ccc}
\hline Gender & Old Campus (\% of Sample) & New Campus (\% of Sample) \\
\hline Male & 50.9 & 61.3 \\
Female & 49.1 & 39.7 \\
\hline Grade & & \\
\hline Undergraduate & 34.5 & 44.5 \\
Graduate & 34.5 & 33.5 \\
PhD candidate & 31 & 22 \\
\hline
\end{tabular}




\subsection{The Optimization Method of Walk Score}

\subsubsection{Establishing the Weight of Facility}

The researchers sorted the common public service facilities that students always use into 13 types:

1. canteen and restaurant

2. public teaching building,

3. retail store,

4. gym,

5. library,

6. square and green space,

7. bus station,

8. outdoor stadium,

9. coffee shop,

10. student activity center,

11. bank and post office,

12. administrative building,

13. barber shop.

This research used the optimization method from scholars Lu and Huang to modify the weight of facility table, which includes three factors: 1 . establishing the diversity of facilities; 2 . completing the demand distribution of diversity; and 3. calculating the satisfaction of requirements of classified facility [49,64].

Through the questionnaire, the number and average using frequency per week of various facilities were counted, dividing the facilities into high frequency type (more than five times a week), medium frequency type (more than one time a week), and low frequency type (less than one time a week). The data related to each type were listed in a facility table (Table 2).

Table 2. The diversity of facilities.

\begin{tabular}{|c|c|c|c|c|c|c|c|c|c|}
\hline \multirow{2}{*}{ The Type of Facilities } & \multirow{2}{*}{$\begin{array}{c}\text { Using } \\
\text { Frequency }\end{array}$} & \multicolumn{7}{|c|}{ Facilities are Numbered in Order of Distance from Near and Far } & \multirow{2}{*}{$\begin{array}{c}\text { Diversity } \\
\text { Value }\end{array}$} \\
\hline & & 1 & 2 & 3 & 4 & 5 & 6 & 7 & \\
\hline Canteen and restaurant & 21 & 21.49 & 20.02 & 18.22 & 13.17 & 11.86 & 11.86 & 3.38 & 6 \\
\hline Public teaching building & 5.06 & 36.74 & 34.73 & 28.53 & & & & & 3 \\
\hline Retail store & 4.31 & 20.39 & 17.32 & 14.24 & 14.04 & 12.91 & 11.55 & 9.55 & 6 \\
\hline Square and green space & 2 & 24.06 & 22.52 & 17.43 & 16.99 & 11.92 & 7.08 & & 5 \\
\hline Bus stop & 1.81 & 100 & & & & & & & 1 \\
\hline Outdoor stadium & 1.4 & 66.56 & 33.44 & & & & & & 2 \\
\hline Administrative building & 0.86 & 100 & & & & & & & 1 \\
\hline Barber shop & 0.25 & 39.28 & 33.93 & 26.79 & & & & & 3 \\
\hline
\end{tabular}

The services provided by different shops in the same kind of facility may vary. Therefore, the greater the number of facilities, the more diverse the services provided, and the higher the satisfaction of the demand for this facility type. Facilities of the same type are listed in order of descending proportion of service. Considering the main services supplied by the facilities and eliminating facilities that are 
only used by very few students, the value of demand diversity was decided by the number of facilities accounting for $90 \%$ of the total proportion $[49,64]$ (Table 2). For example, for the canteen and restaurant, these facilities are used 21 times a week and the proportion of each individual facility use frequency to the overall use frequency is $21.49 \%, 20.02 \%, 18.22 \%, 13.17 \%, 11.86 \%, 11.86 \%$, and $3.38 \%$, respectively. Because the sum of the proportions of the first six facilities (96.62\%) exceeded $90 \%$, we defined the value of demand diversity of the canteen and restaurant as 6 .

The weight or relative importance of classified facilities came from counting the frequency of use of all facilities, calculating the proportion of facilities' use frequency to the total frequency, and then multiplying by 100 . According to the diversity value, the weight of a facility was allocated to different instances of the same kind, based on the proportion of servicing, which determined the weight of every facility (Table 3).

Table 3. The weight of each facility and the demand distribution of diversity.

\begin{tabular}{|c|c|c|c|c|c|c|c|c|}
\hline \multirow{2}{*}{ The Type of Facilities } & \multirow{2}{*}{$\begin{array}{l}\text { Weight of } \\
\text { Facilities }\end{array}$} & \multirow{2}{*}{$\begin{array}{c}\text { Diversity } \\
\text { Value }\end{array}$} & \multicolumn{6}{|c|}{ Demand Distribution of Diversity } \\
\hline & & & Facility 1 & Facility 2 & Facility 3 & Facility 4 & Facility 5 & Facility 6 \\
\hline Canteen and restaurant & 47.54 & 6 & 10.57 & 9.85 & 8.96 & 6.48 & 2.33 & 2.33 \\
\hline Retail store & 9.76 & 5 & 2.2 & 1.87 & 1.54 & 1.51 & 1.39 & 1.25 \\
\hline Gym & 4.71 & 1 & 4.71 & & & & & \\
\hline Square and green space & 4.53 & 5 & 1.17 & 1.1 & 0.85 & 0.83 & 0.58 & \\
\hline Bus stop & 4.1 & 1 & 4.1 & & & & & \\
\hline Outdoor stadium & 3.17 & 2 & 2.11 & 1.06 & & & & \\
\hline Coffee shop & 2.98 & 1 & 2.98 & & & & & \\
\hline Barber shop & 0.56 & 3 & 0.22 & 0.19 & 0.15 & & & \\
\hline Sum & 100 & & & & & & & \\
\hline
\end{tabular}

\subsubsection{Fitting the Curve of Time-Decay}

The curve of time-decay expresses the relationship between walking time and pedestrian's walking intention. The Walk Score evaluation system regards $5 \mathrm{~min}$ as the comfortable walking time, that is, the intention to walk does not decline within this time. However, with the increase of time, it decays rapidly, and when it reaches $20 \mathrm{~min}$, it decays to $12 \%$ of the initial walking intention. When the time continues to increase, the attenuation rate continues to slow until the time exceeds $30 \mathrm{~min}$, and the attenuation rate is bigger than 1 , which means pedestrians will not likely walk to the destination any more (Walk Score ${ }^{\circledR}$ 2011).

However, this classification is not suitable for all people, especially for university students. Accordingly, this research used questionnaires to address the range of comfortable walking time (within this time, the intention of walking to facilities will not decrease with the increase of distance), tolerance time (from comfortable time to this time, the willingness to walk will decrease), and resistance time (beyond this time, students are no longer willing to walk to public facilities) for each kind of facility. After averaging the data of students' evaluation of the three types of time intervals of accessing to different facilities, we divided the intervals of time decay into three categories (walking time, tolerance time, and resistance time, respectively) based on the data from the questionnaires. $1.6 \mathrm{~m}, 17 \mathrm{~m}, 24 \mathrm{~m}$, facility: Public teaching building, canteen and restaurant, bus stop, retail store. $2.7 \mathrm{~m}, 18 \mathrm{~m}, 24 \mathrm{~m}$ facility: Library, coffee shop, bank and post office, square and green land. $3.8 \mathrm{~m}, 17 \mathrm{~m}, 24 \mathrm{~m}$ facility: gym and outdoor stadium. For a retail store, for example, if the walking time from the starting point to the facility is less than $6 \mathrm{~min}$, there is no weight attenuation, but as the time increases to $17 \mathrm{~min}$, 
the weight decays to $12 \%$ of its original value. However, when the time exceeds $24 \mathrm{~min}$, the weight and the final score will decrease to 0 .

\subsubsection{Calculating Campus Walk Score}

After establishing the weight of each facility and fitting the final curve of time-decay according to these categories, we preliminarily calculated the campus Walk Score, based on the two factors, to achieve a raw score. Subsequently, we took the block length and intersection density around each origin into account and the areas with poor pedestrian friendliness were penalized a certain percentage of what they would have scored. A maximum $5 \%$ penalty for $<60$ intersections per square mile and the Walk Score average block length function was used to deduct the same maximum of $5 \%$ for $>195 \mathrm{~m}$ length per block (Walk Score ${ }^{\circledR}$ 2011) [65]. Considering that the campus fabric and campus form are quite different from a city environment, the scale is smaller than a city scale. Therefore, the intersection density and average block length were calculated by drawing a 200-m buffer around each point in the study, counting the number of intersections, and calculating the total block length. Finally, we calculated the score of each classified facility and summed the 13 sub-scores to get the overall campus Walk Score. Additionally, we used the spatial interpolation function of ArcGIS geospatial software to get the visualized Walk Score outcome.

\section{Results}

\subsection{Overall Evaluation}

By calculation, the Walk Score of the old campus is 90 , and that of the new campus is 73 . In general, the two campuses both have high pedestrian accessibility. The old campus especially reached the highest standard of Walk Score rating standard (Walk Score ${ }^{\circledR}$ 2011), and students and staff can completely meet their daily needs by walking. However, due to the differences of campus locations and the planning and layout of their facilities, the walking accessibility of the two campuses is quite different in the spatial pattern of the calculations (Figure 3).

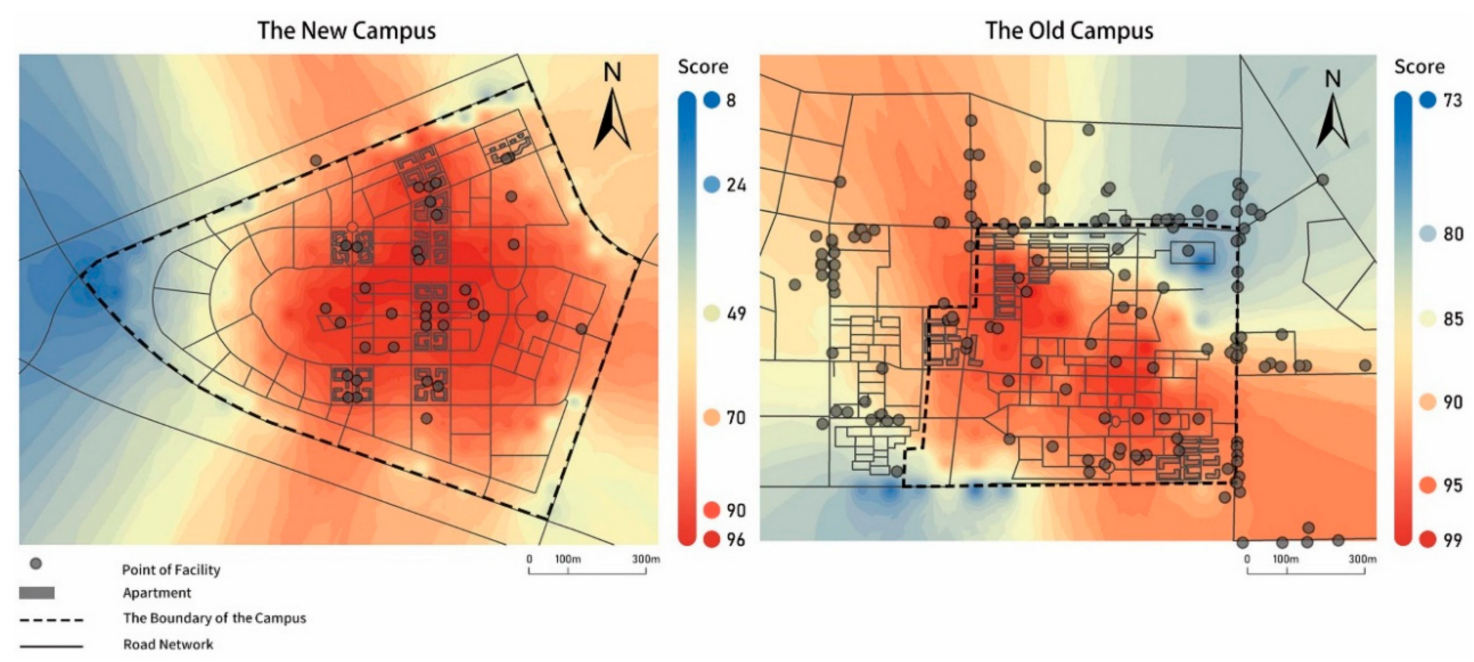

Figure 3. The Walk Score of the two campuses.

The pattern of the new campus' Walk Score distributes pedestrian activity in the core of the campus:

1. The core island group in the campus center has the highest value. It can be seen from the detailed subdivision level that the central area has the library, public teaching buildings, retail stores, restaurants, and other facilities. Students from the north (Pingyuan, Zhiyuan, Chengyuan group) or the south (Zhiyuan, Qiyuan group) and the middle (Zhengyuan, Xiuyuan group) areas can reach those facilities walking within $500 \mathrm{~m}$, without the decline in willingness to walk due to a long distance. 
2. The value decreases gradually from the center to the periphery area until the marginal area has quite low walkability. The reason is that the centralized layout of the facilities causes the imbalance in the number and allocation of the facilities in the surrounding area. In addition, the geographical location of the campus is another factor that leads to the continuous decrease of the Walk Score. Because most of the surrounding area has vacant lots or agricultural land, with zero off-campus public services, there is also a sharp decrease of this area's Walk Score.

3. There is a very low value (blue area) on the west side of the campus. At present, this area is used for future development, without any facilities, so the walkability here is poor.

In contrast, the pattern of Walk Score of the old, multi-centered campus is evenly distributed:

1. Due to the uniform distribution of facilities in the campus and its attachment to the small-scale group center, the whole campus has a high Walk Score, and students can walk conveniently to the nearby facilities in a short time.

2. The edge area of the campus also has high walkability, because this campus is located in the center of the city, and the surrounding roads have a variety of facilities to meet the daily demands of students. Take the north Anshan West Road as an example: there are many kinds of facilities on the first floor of the buildings, with various functions (such as a convenience store, restaurant, and coffee shop), a dense flow of people, small storefronts, and no large-scale shopping mall to destroy the rhythm of the layout. The streets in the residential area extend to Anshan West Road, injecting a continuous flow of people to promote street vitality. At the same time, the dormitory group located next to Anshan West Road, because of its superior location, lets students walk a short distance to their destinations, which greatly meets the students' choice of facility diversity.

3. However, the area around the gym, which is situated in the northeast of the campus, has a low Walk Score. This is because this area has only one gym, and it is surrounded by a continuous wall to form a closed domain. Pedestrians come from outside the campus need to walk a long distance to get there, so the Walk Score of this area is reduced.

\subsection{Evaluation of Classified Facilities}

By calculating the Walk Score of the classified facilities, we can find out which type affects the overall walkability of campus. The distribution pattern of the score of each type in the campus can be seen directly (Figure 4). Additionally, for the similar Walk Score of certain facilities, we can also make comparisons through the standard deviation (SD) value. For the new campus, retail stores, restaurants, coffee shop, and other facilities are evenly distributed, and the high-value red area basically covers the whole campus. However, the layout of bus stops and gym is out of balance, which only meets the students' needs in the area where the facilities are located, while other areas have very low walkability. From Table 4, we can tell the two lowest demand satisfaction rates of gym and bus stop are $49 \%$ and $39 \%$. Therefore, future improvements need to pay attention to the walkability of the bus stop and gym.

Full score: The full Walk Score of each classified facility and the sum of each classified facility's full score is 100. Actual score: The mean value of the actual Walk Score of each classified facility, calculated based on the actual facility layout and street network. Standard deviation: the standard deviation of the actual score of each classified facility. Demand satisfaction rate: the ratio of actual score to full score, which means that the higher the ratio, the better balance between the service supplied by the facilities and students' daily demands.

For the old campus, in addition to improving the Walk Score of the gym, the Walk Score of other facilities reached a high value. Generally, there is a balance between the classified facilities' service and students' needs. From Table 4, we can more accurately find the satisfaction rate of various facilities and the standard deviation of a classified facility's Walk Score, which are much higher than those of the new campus. However, both the satisfaction rate of the gym and outdoor stadium are lower than the other facility's, which are 0.58 and 0.66 , respectively. Furthermore, although the satisfaction rate of the canteen and restaurant is 0.94 , the standard deviation of the Walk Score of these facilities is high (5.1), which means that the facility layout is not balanced, influencing proximity. In order to promote 
the overall walkability, the university should pay attention to the balance of the layout of various facilities and the diversity of functions in the later planning and design phases, so as to improve the convenience of students in using public service facilities.

The results discussed above are similar to results from some previous Walk Score studies that utilized other optimized Walk Score methods [42,47-53]. We found a close association between Walk Score and facility layout, with walkability considerably improved if an area has a variety and density of facility types, a decentralized facility layout, and a highly permeable boundary [47-50]. Moreover, our findings also accord with the related findings from other campus walkability studies that used both subjective and objective methods, including surveys of participants' perceptions of campus walkability and field audits of the campus built-environment features [21,57,59,61]. For instance, some researchers also found that high proximity to walkable campus destinations will promote campus walkability and encourage students to walk $[21,59,61]$. They also found that the higher walkability streets are located in the oldest campus areas with a well-developed walking street network, while the worst walking paths are the main roads around the campus [57]. As described earlier, the built environment of these two Tianjin University campuses is significantly different in terms of their providing a pedestrian-oriented, walkable environment and our results have shown how the built environment can promote campus walkability and trigger walking behavior [66]. After reviewing 50 American campus master plans, Hajrasouliha found that promoting walkability is the main goal in all the reviewed campus plans [67].

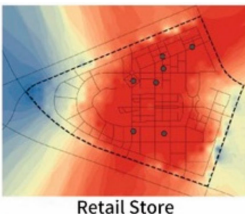

Retail Store
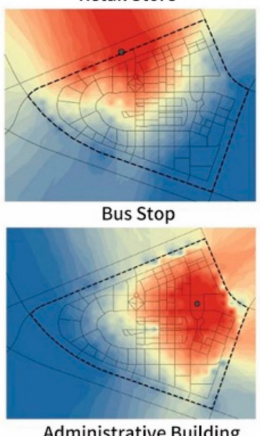

Administrative Building

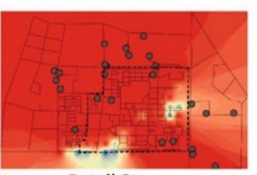

Retail Store

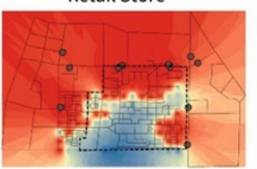

Bus Stop

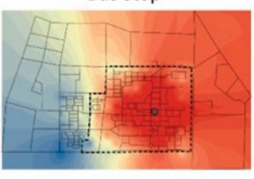

Administrative Building

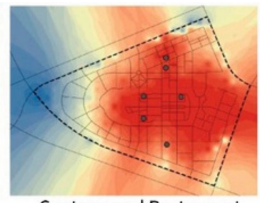

Canteen and Restaurant

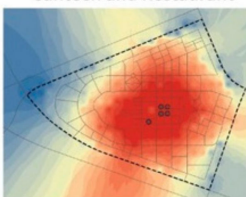

Public Teaching Building

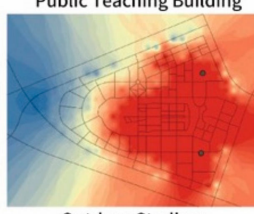

Outdoor Stadium
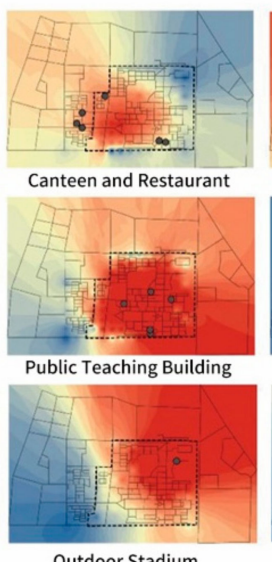

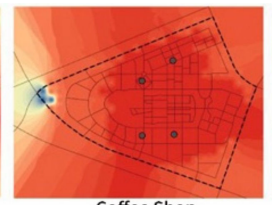

Coffee Shop
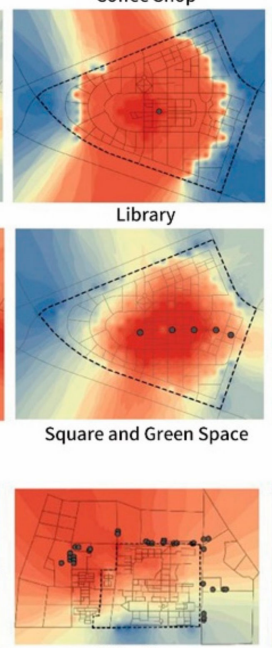

Coffee Shop

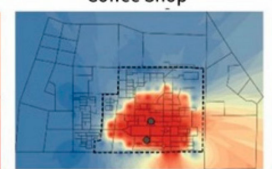

Library

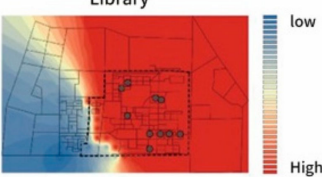

Square and Green Space

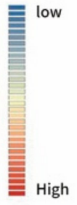

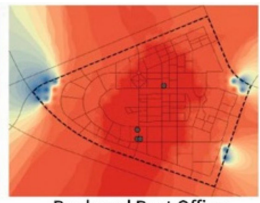

Bank and Post Office

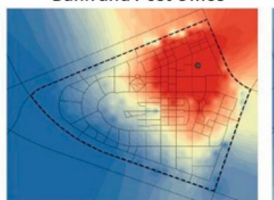

Gym

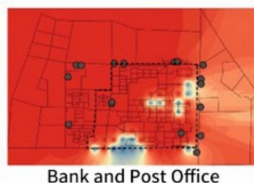

Bank and Post Office

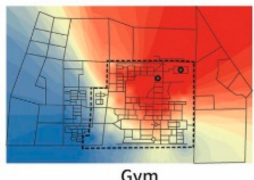

Gym

The New Campus

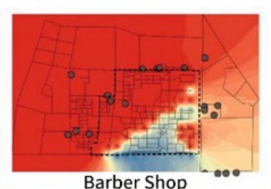

Barber Shop

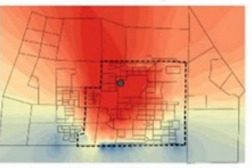

Student Activity Center

The Old Campus

Figure 4. The Walk Score of the classified facilities in the two campuses. 
Table 4. The demand satisfaction rate of each facility.

\begin{tabular}{|c|c|c|c|c|c|c|c|c|}
\hline \multirow[b]{2}{*}{ The Type of Facility } & \multicolumn{4}{|c|}{ The New Campus } & \multicolumn{4}{|c|}{ The Old Campus } \\
\hline & $\begin{array}{l}\text { Full } \\
\text { Score }\end{array}$ & $\begin{array}{l}\text { Actual Score } \\
\text { (Mean) }\end{array}$ & SD & $\begin{array}{c}\text { Demand } \\
\text { Satisfaction Rate }\end{array}$ & $\begin{array}{l}\text { Full } \\
\text { Score }\end{array}$ & $\begin{array}{l}\text { Actual Score } \\
\text { (Mean) }\end{array}$ & SD & $\begin{array}{c}\text { Demand } \\
\text { Satisfaction Rate }\end{array}$ \\
\hline Canteen and restaurant & 47.54 & 36.26 & 11.1 & 0.76 & 43.93 & 41.13 & 5.84 & 0.94 \\
\hline Public teaching building & 11.46 & 7.53 & 3.04 & 0.66 & 13.59 & 12.52 & 1.51 & 0.92 \\
\hline Retail store & 9.76 & 8.17 & 2.13 & 0.84 & 11.37 & 11.21 & 0.46 & 0.98 \\
\hline Gym & 4.71 & 2.3 & 1.64 & 0.49 & 4.06 & 2.37 & 0.87 & 0.58 \\
\hline Square and green space & 4.53 & 4.08 & 0.73 & 0.9 & 3.71 & 3.61 & 0.17 & 0.97 \\
\hline Bus stop & 4.1 & 1.58 & 1.23 & 0.39 & 3.12 & 2.95 & 0.16 & 0.95 \\
\hline Outdoor stadium & 3.17 & 2.46 & 0.88 & 0.78 & 4.15 & 2.74 & 1.25 & 0.66 \\
\hline Coffee shop & 2.98 & 2.85 & 0.28 & 0.95 & 4.26 & 3.18 & 0.03 & 0.75 \\
\hline Barber shop & 0.56 & 0.51 & 0.09 & 0.91 & 0.49 & 0.48 & 0.02 & 0.98 \\
\hline
\end{tabular}

Other researchers have combined students' mode choice, social interaction, physical activity, and other variables with proximity to facilities to illustrate the campus environments' effect on walkability and students' college life [68-74]. For instance, Lau and associates found that when campus open spaces are easy to access, they promote social interaction [68]. Likewise, Hipp et al. found that a high level of campus green space can improve students' quality of life [69]. Furthermore, Horacek et al. found that the walkable campus environment has a relationship with students' walking behavior and their body mass index (BMI) [20]. Accordingly, Slater et al. found that students living in pedestrian-friendly communities have reduced odds of being overweight or obese [71]. After a 15-year longitudinal study, Gordon-Larsen and colleagues also found that if young adults keep walking throughout adulthood, they may reduce the odds of being overweight [72]. These pieces of evidence strengthen the importance of proximity to facilities and pedestrian-oriented environments for college students' daily life [68-72].

\subsection{Walkability Optimization}

From the analysis of the current situation of the old campus, we can see that the Walk Score is high and the overall walkability of the campus is good. Consequently, this paper takes the new campus as an example and optimizes its low walkable area based on the evaluation results of the classified facilities. In the optimization scheme, we need to meet the students' requirements for living convenience and walking behavior from two aspects: the diversity of facilities and the rationality of spatial layout. Because the Walk Score of the bus stop and gym restrict the improvement of walkability in the new campus, this paper takes the measure of increasing the number of bus stops and gyms to meet the students' needs for the varieties of facilities. Due to the general characteristics of the closed boundary in Chinese campuses, facilities are located around the campus gates, with apartments located next to the south gate. Therefore, for the convenience of students' travel, in the optimization scheme, we located the added bus stop on the south side, next to the south gate of the campus.

To improve the gym's Walk Score, we took into account that many comprehensive campus gyms just take the area's index into consideration and always omit the location layout and the proximity. Furthermore, from the surveys we know that students' primary purpose to go to the gym is to play badminton and for a workout. Additionally, this paper used the GIS network-analysis function to compare the added locations based on the actual street distance from the buffer of the walking resistance distance of the current gym location. Consequently, we located a new, small gym containing badminton courts and fitness facilities on the west side of the future development land, which is close to the student apartments and can provide the service for future buildings. Simultaneously, it can help to balance the demand pressure of student groups from the south and central part of the campus. 
We then carried out a new round of Walk Score calculation for the new optimization scheme (Figure 5). With the score of the gym increased from 39 to 72, and the score of the bus station increased from 49 to 83 , the walkability of these two types of facilities greatly improved. Moreover, the total Walk Score of the campus also increased from 71 to 79 . It can be seen from the figure that the red, high-value area in the center of the campus is further expanded. The walkability of the central and south areas rose to the top level of Walk Score (walker's paradise). The promoted areas also correlated well with the students' population density. In addition to the low-value (blue) area in the west, the walkability of the whole campus has been improved.

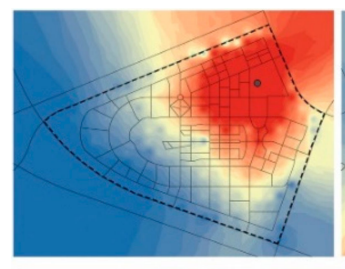

A1

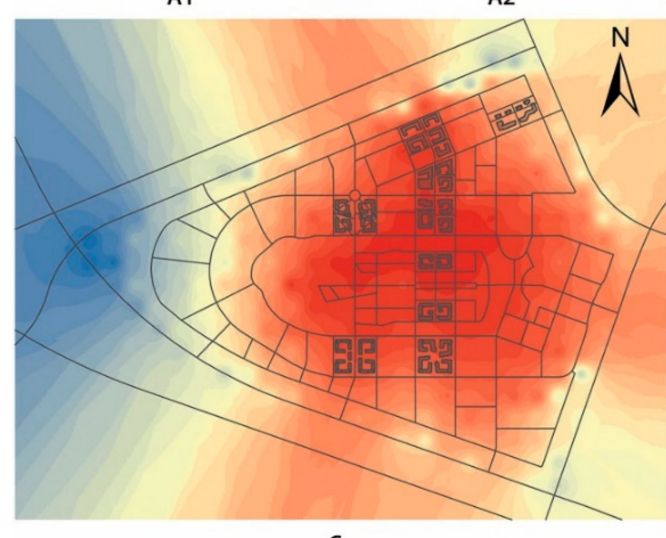

C

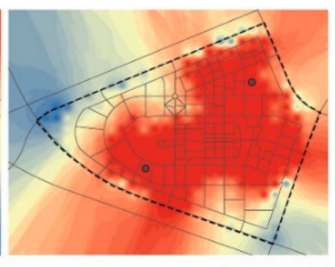

A2

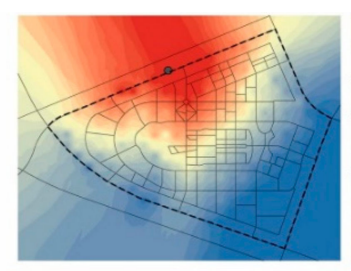

B1

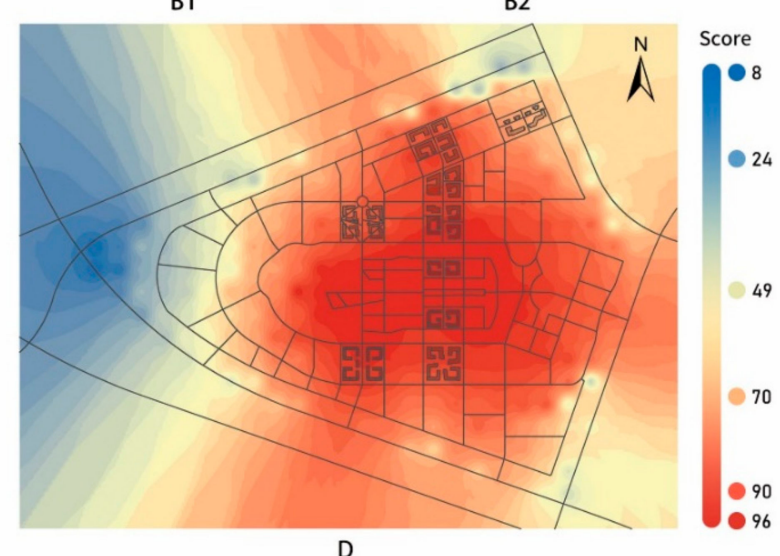

D

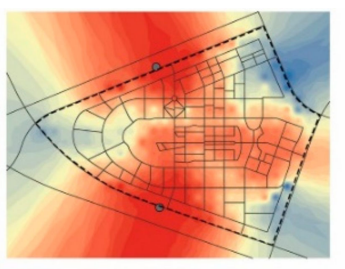

B2

Figure 5. Changes of Walk Score after being improved. (A1) Existing condition; (A2) Proposed change. The score of the gym increased from 39 to 72; (B1) Existing condition; (B2) Proposed change. The score of the bus station increased from 49 to 83 ; (C,D) The total Walk Score of campus increased from 71 to 79.

Other researchers also emphasize the effects of the proximity to exercise facilities on students walking behavior and physical activity [60,61,73-75]. Reed and Phillips found that the proximity of exercise facilities positively influenced students' physical activity behavior and individual decisions to exercise [61]. Likewise, Sallis and colleagues found that residents are more likely to exercise when facilities are near their homes [73]. Furthermore, when the walking time from residents' residences to the nearby facilities becomes shorter, the residents' walk-related stress will be reduced [60]. However, Reed also found that some university students are not aware of the available physical activity facilities on the campus and perceive having access to fewer campus exercise facilities [74]. Moreover, Hajrasouliha also mentioned that if the sports facilities are far away from the campus, it will decrease the possibility of their being used by students [67]. Moreover, Zhou found that university students prefer to share a residence with others due to the benefit of bus proximity and short commute [70]. Thus, it is essential to improve the proximity to exercise and bus facilities on the campus, and it will help reduce the students' physical and psychological barriers to exercise and promote physical activity [75]. These pieces of evidence support the new optimized scheme presented in this research $[60,61,73-75]$.

\section{Discussion}

In terms of the characteristics of campus walking behavior and student actual needs of using public service facilities, this paper presents a campus walkability measuring tool based on the optimized method of Walk Score from the overall and individual assessment level. Based on this method, we measure the walkability of the new and old campus of Tianjin University to test the validity of 
this method and to explore the relationship between Walk Score and the layout pattern of public service facilities. In addition, we compare the walkability differences caused by the campus geographic location, planning form, and type of facilities. By taking the measures of adding the number of facilities and adjusting its layout, we put forward a reasonable optimization scheme for the campus planning and design.

Based on the overall results, we found that the old, multi-centered campus with a compact campus structure, located in the city center, has a higher walkability level than the new suburban campus. This result is consistent with the outcome from Glazier et al.'s Walk Score research. They found that the inner-city neighborhoods with compact urban fabric and mixed land uses have a higher walkability level than those neighborhoods located in suburbs [38]. Moreover, for the association between facility layout and campus walkability, we also get a similar result with Huang et al.'s research, which uses another optimized Walk Score method aiming for the elderly to analyze the effect of facility layout on neighborhood walkability [49]. Both found that the walk score of the areas with decentralized facilities is higher than those with centralized ones. This general outcome also accords with related findings from studies such as Sisson, who found students in campuses with many on-campus destinations and situated on a grid of streets are more likely to walk and rated that the campus has a higher walkability level than those in the campus with limited number of nearby facilities and most streets open to motorized traffic [21]. Another study found that due to the better destination proximity, on-campus built environments can promote more physical activity than off-campus environments [59]. Additionally, Lu et al.'s findings show that the walkability of areas with high-use frequency facilities is higher than those with middle- or low-use facilities [48]. In addition, we discovered the campus enclosing wall impedes the walkability of its surrounded areas, particularly the northeast region in the old campus, and accordingly, Liu also found that regions with good permeable boundaries have a better walkability level [53]. Furthermore, research shows that more traditional architectures provide a better learning environment due to their close connection with human cognition through its fractal structures and symmetrical form [18]. Accordingly, we also found that the walkability of the historical buildings areas has a higher walkability than the contemporary building areas on the old campus. Furthermore, through calculating the Walk Score of classified facilities, we can more accurately diagnose the impact of the number of facilities and the layout mode on Walk Score. We found that the standard deviation value of the overall Walk Score is higher than that of each classified facility, which means that there are big differences between the overall facility service capability and classified facility's service capability. Additionally, this outcome aligns with Tsou's study, which also found that the standard deviation value of aggregated facility levels is lower than the disaggregated facility level when using different walkability measurement methods [14].

\section{Conclusions}

The following three conclusions and suggestions can be drawn from this study:

1. This optimized Walk Score tool can evaluate the walkability of campus and the rationality of facility layout. Additionally, this method can not only calculate the campus Walk Score, which can be predicted intuitively (for example, it is easy to tell that the Walk Score of the campus peripheral areas close to many facilities is better than that of the campus located in the suburb, with fewer facilities around it), but also measure the walkability of different campuses with similar facilities, which are difficult to evaluate intuitively (the comparison of the Walk Score of the campus with the same facility's type and number and similar layout patterns). All of the components contained in this campus walkability metric are also used in other walkability indices [12,23,35-40,42]. Particularly, intersection density is the feature of many indices utilized in different study areas [12,23,35,38,39,42]. However, to date, most studies using different optimized Walk Score methods only evaluate the areas' current walkability conditions and present the associated optimized suggestions, but they seldom use the tool to reevaluate those suggestions' suitability [42,47-53]. As Frank et al. said, the walkability metric should be applied to identify priority areas for future redevelopment and to 
monitor the space and form changes [35]. Consequently, for urban planners and campus designers, they can use this quantitative measurement tool to evaluate the walkability of specific urban areas (university towns, education zones) and an existing campus, and to test whether the number and distribution of university facilities meet the basic needs of students' daily life. Furthermore, through the data visualization function of GIS, planners can further intuitively diagnose the reasons why certain areas have low walkability through the evaluation results of classified facilities and present the optimizing suggestions based on the outcomes. Specifically, planners can improve the walkability of the least walkable areas and secondarily make the walkable areas more walkable [40]. Moreover, the Walk Score of the new optimization scheme can be recalculated to test the rationality of the new scheme through the site review process [40]. Therefore, it can also be used as a process of "evaluation-diagnosis-optimization-re-evaluation-re-diagnosis-re-optimization" to make the campus more walkable and sustainable and act as a vital determinant to complement the current assessment system of green campuses.

2. The walkability of the multi-center layout of the old campus is better than the centralized layout of the new campus. Therefore, in terms of campus facilities layout, the decentralized layout lets the facility attach to the various functional centers, and locate facilities closely related to the apartment groups, so as to meet the students' needs for the type and quantity of facilities. Campus planners can adjust the facility layout using the least amount allocated at the proper location to serve the largest population of students. Planners can also control the campus size to reduce the occupation of large amounts of land and the waste of resources, improving the sustainable development of the green campus. Although this walkability metric has been tested by the case study of the two campuses, researchers can also verify the validity of this tool in different types and sizes of universities, based on investigating the association between Walk Score and the number of walkable destinations, street connectivity, land use mix, student's perceptions of the walking environment, and the relationship between the actual walkability and the calculated walkability $[5,6,43,45,76,77]$. Like other neighborhood Walk Score studies, this tool can also be used to investigate the association of campus Walk Score and a series of outcomes, such as students' walking behavior, physical activity, travel mode, housing options, college life satisfaction, academic performance, social capital, etc. [56,58,59,67-74,78]. Meanwhile, researchers can use this tool to conduct quantitative research into the walkability of other campuses in different regions and with different scales. Importantly, incorporating the criteria of Walk Score into the design guidelines of campus planning and urban planning of an Education Zone is imperative to improve the design and planning methods of university campuses from the three aspects of 1 . the sustainable campus environment, 2. positive and healthy learning and living, and 3. environmental protection and low-carbon travel modes. Other than that, this tool can also be applied to other city areas and for specific population groups through combining the areas' specific built-environment characteristics and certain people's facility use requirements to optimize this walkability measurement tool. As Taleai et al. and Peiravian et al. mentioned, planners can use the further optimized tool to measure and rank the walkability of already-built environments, reveal deficiencies in their urban design, and further identify the areas that have low walkability and low economic activities and the imbalances between supply and demand for social services within those areas [13,23].

3. The diversified distribution of the facilities around the surrounding area of the old campus will promote the walkability of its periphery places. As Salingaros said, campuses should not be surrounded by a boundary and isolated from a region of the city; instead, they should connect with the city environment [79]. Therefore, for the planning, location, and construction of the surrounding environment, the edge area of the campus should be closely connected to streets with high mixed functions and good facility diversity to improve the vitality of the campus and the living convenience and life satisfaction of students. For policy makers, when there is a demand to build a new campus, they can also use this tool to calculate the Walk Score of the new campus plan, and use the Walk Score as an important index to evaluate the walkability of the scheme. This tool can provide powerful data support to compare different sites where there are many living streets with a variety of surrounding 
facilities and to adjust the scheme to achieve a balance between student demands and the facility's supply for service. For an existing campus, with compact places and mixed use but a low walkability level, this tool can help policy makers detect the reasons why and target improvements to the campus boundary to make it more permeable by adding gates or getting rid of campus walls, and to improve the street connectivity by connecting cul-de-sacs or completing sidewalks. In addition, when there is a need to construct a student apartment, this tool can also help policy makers choose a site that has a high Walk Score, which can improve students' access to facilities. As Vale et al. said, if the student apartments and local facilities are provided in the campus walkable areas, it will make students more likely to walk and cycle to the campus [63]. Additionally, Peiravian et al. also concluded that the walkability measurement tool could help planners evaluate the walkability of future developments and select ones that can provide a more walkable environment for pedestrian activities and thus reduce their dependence on motor vehicles [23]. However, researchers also mentioned that campuses are gradually losing their distinct character, identity, and specific culture if they merely adopt unified master plans and generic recommendations $[18,67]$. Therefore, campus planners can also combine this tool with Salingaros' "walkabout" method to take the intuitive and visceral sense of place of campus users (students, teachers, staff) into consideration to transform the existing built campus or design a new campus plan that elicits unexpected design features spontaneously. In summary, this tool can provide a robust framework for policy makers to reconceive new, welcoming campuses and to repair the problematic spaces on the existing campuses, based on their walkability and psychological impact on users, while improving the final decision-making process [18].

There are many limitations of this research. On the one hand, the disparities between the subjective cognition and the objective evaluation fail to reflect some subjective requirements of the walking experience, such as a sense of comfort and a sense of safety [55]. On the other hand, this tool only considers the actual student's use conditions based on walking time, walking frequency, intersection density, and block length. The campus' land use mix, circuity, campus morphology, and street design qualities (e.g., legibility, imageability, enclosure, etc.) have not been taken into account in this methodology. Moreover, other researchers found that students are more likely to walk on campus paths, and their perceptions of the quality of campus paths' condition will encourage them to walk across the campus $[62,80]$. Therefore, the influence of sidewalk presence and condition on students' walking behavior should be closely investigated in future studies.

In the following study, there are at least three areas for future research:

1. In a follow-up study, we need to further combine the effect of land use and street pattern features on Walk Score, and apply urban design theory to analyze the association between various qualities on Walk Score, to improve the campus Walk Score methodology [67-69,81,82].

2. Future research also needs to explore areas where the subjective cognition of walkability is inconsistent with the Walk Score and to measure the degree of this inconsistency. By studying the relationship between streetscape characteristics, urban design qualities, and Walk Score, future research can find out if there is a positive association between the street environmental features and Walk Score, in order to further check the validity of this evaluation method and make accurate assessments of specific areas' walkability [55,81-84].

3. Finally, future research needs to study street environmental behavior, and observe and record pedestrian volume and behavior at the micro-scale level in order to explore its association with Walk Score and to determine the degree to which the walkability results calculated from the Walk Score reflect the students' actual walking behavior and walking intention.

Author Contributions: Z.Z. conceived and conducted the research, analyzed the data, and wrote the paper; T.F. reviewed and edited the paper; T.F. and G.F. made several comments and suggestions. All authors have read and agreed to the published version of the manuscript.

Funding: This research received no external funding.

Conflicts of Interest: The authors declare no conflict of interest. 


\section{References}

1. Huang, J.; Hu, G. Comparison and thinking of the walkability measure methods on urban built environment. J. Hum. Settl. West China 2016, 31, 43-47.

2. Sohn, D.W.; Moudon, A.V.; Lee, J. The economic value of walkable neighborhoods. Urban Des. Int. 2012, 17, 115-128. [CrossRef]

3. Leyden, K.M. Social Capital and the Built Environment: The Importance of Walkable Neighborhoods. Am. J. Public Health 2003, 93, 1546-1551. [CrossRef] [PubMed]

4. Hall, C.M.; Ram, Y. Walk score®and its potential contribution to the study of active transport and walkability: A critical and systematic review. Transp. Res. Part D Transp. Environ. 2018, 61, 310-324. [CrossRef]

5. Carr, L.J.; Dunsiger, S.; Marcus, B.H. Validation of Walk Score for estimating access to walkable amenities. Br. J. Sports Med. 2011, 45, 1144-1148. [CrossRef]

6. Duncan, D.T.; Aldstadt, J.; Whalen, J.; Melly, S.J.; Gortmaker, S.L. Validation of Walk Score®for Estimating Neighborhood Walkability: An Analysis of Four US Metropolitan Areas. Int. J. Environ. Res. Public Health 2011, 8, 4160-4179. [CrossRef]

7. Hajna, S.; Ross, N.; Joseph, L.; Harper, S.; Dasgupta, K. Neighbourhood walkability, daily steps and utilitarian walking in Canadian adults. BMJ Open 2015, 5, e008964. [CrossRef]

8. Ariffin, R.N.R.; Zahari, R.K. Perceptions of the Urban Walking Environments. Proc. Soc. Behav. Sci. 2013, 105, 589-597. [CrossRef]

9. Forsyth, A. What is a walkable place? The walkability debate in urban design. Urban Des. Int. 2015, 20, 274-292. [CrossRef]

10. Reyer, M.; Fina, S.; Siedentop, S.; Schlicht, W. Walkability is Only Part of the Story: Walking for Transportation in Stuttgart, Germany. Int. J. Environ. Res. Public Health 2014, 11, 5849-5865. [CrossRef]

11. Pivo, G.; Fisher, J.D. The Walkability Premium in Commercial Real Estate Investments. Real Estate Econ. 2011, 39, 185-219. [CrossRef]

12. Frank, L.D.; Schmid, T.L.; Sallis, J.F.; Chapman, J.; Saelens, B.E. Linking objectively measured physical activity with objectively measured urban form: Findings from SMARTRAQ. Am. J. Prev. Med. 2005, 28, 117-125. [CrossRef] [PubMed]

13. Taleai, M.; Sliuzas, R.; Flacke, J. An integrated framework to evaluate the equity of urban public facilities using spatial multi-criteria analysis. Cities 2014, 40, 56-69. [CrossRef]

14. Tsou, K.-W.; Hung, Y.-T.; Chang, Y.-L. An accessibility-based integrated measure of relative spatial equity in urban public facilities. Cities 2005, 22, 424-435. [CrossRef]

15. Vale, D.S.; Saraiva, M.; Pereira, M. Active accessibility: A review of operational measures of walking and cycling accessibility. J. Transp. Land Use 2015, 9, 209-235. [CrossRef]

16. Oh, K.; Jeong, S. Assessing the spatial distribution of urban parks using GIS. Landsc. Urban Plan. 2007, 82, 25-32. [CrossRef]

17. Cubukcu, E.; Hepguzel, B.; Onder, Z.; Tumer, B. Active Living for Sustainable Future: A Model to Measure "Walk Scores" via Geographic Information Systems. Proc. Soc. Behav. Sci. 2015, 168, 229-237. [CrossRef]

18. Salingaros, N. Planning, Complexity, and Welcoming Spaces: The Case of Campus Design, Chapter 18. In Handbook on Planning and Complexity; Gert, R., Claudia, Y., Christian, Z., Eds.; Edward Elgar Publishers: Cheltenham, UK, 2020; pp. 353-372.

19. Bartshe, M.; Coughenour, C.; Pharr, J. Perceived Walkability, Social Capital, and Self-Reported Physical Activity in Las Vegas College Students. Sustainability 2018, 10, 3023. [CrossRef]

20. Horacek, T.M.; Yildirim, E.D.; Kattelmann, K.; Brown, O.; Byrd-Bredbenner, C.; Colby, S.; Greene, G.; Hoerr, S.; Kidd, T.; Koenings, M.M.; et al. Path Analysis of Campus Walkability/Bikeability and College Students' Physical Activity Attitudes, Behaviors, and Body Mass Index. Am. J. Health Promot. 2016, 32, 578-586. [CrossRef]

21. Sisson, S.B.; McClain, J.J.; Tudor-Locke, C. Campus Walkability, Pedometer-Determined Steps, and Moderate-to-Vigorous Physical Activity: A Comparison of 2 University Campuses. J. Am. Coll. Health 2008, 56, 585-592. [CrossRef]

22. Kim, Y.-J.; Woo, A. What's the Score? Walkable Environments and Subsidized Households. Sustainability 2016, 8, 396. [CrossRef] 
23. Peiravian, F.; Derrible, S.; Ijaz, F. Development and application of the Pedestrian Environment Index (PEI). J. Transp. Geogr. 2014, 39, 73-84. [CrossRef]

24. Lamíquiz Patxi, J.; Jorge, L.-D. Effects of built environment on walking at the neighbourhood scale. A new role for street networks by modelling their configurational accessibility? Transp. Res. Part A 2015, 74, 148-163. [CrossRef]

25. Brownson, R.C.; Hoehner, C.M.; Day, K.; Forsyth, A.; Sallis, J.F. Measuring the built environment for physical activity: State of the science. Am. J. Prev. Med. 2009, 36, S99-S123. [CrossRef] [PubMed]

26. Forsyth, A.; Hearst, M.O.; Oakes, J.; Schmitz, K.H. Design and Destinations: Factors Influencing Walking and Total Physical Activity. Urban Stud. 2008, 45, 1973-1996. [CrossRef]

27. Lee, C.; Moudon, A.V. Correlates of Walking for Transportation or Recreation Purposes. J. Phys. Act. Health 2006, 3, S77-S98. [CrossRef]

28. Boeing, G.M. The Morphology and Circuity of Walkable and Drivable Street Networks. SSRN Electron. J. 2018, 271-287. [CrossRef]

29. Ahmadpoor, N.; Smith, A.D.; Heath, T. Rethinking legibility in the era of digital mobile maps: An empirical study. J. Urban Des. 2020, 1-23. [CrossRef]

30. Ahmadpoor, N.; Shahab, S. Spatial Knowledge Acquisition in the Process of Navigation: A Review. Curr. Urban Stud. 2019, 7, 1-19. [CrossRef]

31. Gao, Y.; Shahab, S.; Ahmadpoor, N. Morphology of Urban Villages in China: A Case Study of Dayuan Village in Guangzhou. Urban Sci. 2020, 4, 23. [CrossRef]

32. Saelens, B.E.; Handy, S.L. Built environment correlates of walking: A review. Med. Sci. Sports Exerc. 2008, 40, S550-S566. [CrossRef] [PubMed]

33. McCormack, G.R.; Shiell, A. In search of causality: A systematic review of the relationship between the built environment and physical activity among adults. Int. J. Behav. Nutr. Phys. Act. 2011, 8, 125. [CrossRef] [PubMed]

34. Grasser, G.; Van Dyck, D.; Titze, S.; Stronegger, W. Objectively measured walkability and active transport and weight-related outcomes in adults: A systematic review. Int. J. Public Health 2013, 58, 615-625. [CrossRef] [PubMed]

35. Frank, L.D.; Sallis, J.F.; Saelens, B.E.; Leary, L.; Cain, K.; Conway, T.L.; Hess, P.M. The development of a walkability index: Application to the Neighborhood Quality of Life Study. Br. J. Sports Med. 2010, 44, 924-933. [CrossRef]

36. Kuzmyak, J.; Richard, C.B.; David, S. Use of walk opportunities index to quantify local accessibility. Transp. Res. Rec. 1977, 2006, 145-153. [CrossRef]

37. Saghapour, T.; Moridpour, S.; Thompson, R.G. Measuring Walking Accessibility in Metropolitan Areas. Transp. Res. Rec. J. Transp. Res. Board 2017, 2661, 111-119. [CrossRef]

38. Glazier, R.H.; Weyman, J.T.; Creatore, M.I.; Gozdyra, P.; Moineddin, R.; Matheson, F.I.; Booth, G.L. Development and Validation of an Urban Walkability Index for Toronto; Canada Toronto Community Health Profiles Partnership: Toronto, ON, Canada, 2012; pp. 1-21.

39. Moudon, A.V. Washington State School Walk Score. 2020. Available online: http://hdl.handle.net/1773/45599 (accessed on 20 November 2020).

40. Lee, S.; Lee, S.; Son, H.; Joo, Y. A New Approach for the Evaluation of the Walking Environment. Int. J. Sustain. Transp. 2013, 7, 238-260. [CrossRef]

41. Manaugh, K.; Ahmed, E.-G. Validating walkability indices: How do different households respond to the walkability of their neighborhood? Transp. Res. Part D 2011, 16, 309-315. [CrossRef]

42. Weinberger, R.; Sweet, M.N. Integrating Walkability into Planning Practice. Transp. Res. Rec. J. Transp. Res. Board 2012, 2322, 20-30. [CrossRef]

43. Duncan, D.T.; Aldstadt, J.; Whalen, J.; Melly, S.J. Validation of Walk Scores and Transit Scores for estimating neighborhood walkability and transit availability: A small-area analysis. GeoJournal 2012, 78, 407-416. [CrossRef]

44. Brown, S.C.; Pantin, H.; Lombard, J.; Toro, M.; Huang, S.; Plater-Zyberk, E.; Perrino, T.; Perez-Gomez, G.; Barrera-Allen, L.; Szapocznik, J. Associations with Purposive Walking in Recent Cuban Immigrants. Am. J. Prev. Med. 2013, 45, 202-206. [CrossRef] [PubMed]

45. Carr, L.J.; Dunsiger, S.I.; Marcus, B.H. Walk Score ${ }^{\mathrm{TM}}$ As a Global Estimate of Neighborhood Walkability. Am. J. Prev. Med. 2010, 39, 460-463. [CrossRef] [PubMed] 
46. Koschinsky, J.; Talen, E. Affordable Housing and Walkable Neighborhoods: A National Urban Analysis. Cityscape 2015, 17, 13-56.

47. Wu, J.; Qin, W.; Peng, J.; Li, W. The evaluation of walkability and daily facility distribution reasonability of Futian District, Shenzhen based on Walk Score. Urban Dev. Stud. 2014, 10, 49-56.

48. Lu, Y. Walkability Evaluation Based on People's Use of Facilities by Walking. Urban Plan. Forum 2013, 5, 113-118.

49. Huang, J.; Hu, G.; Li, M. The Allocative Suitability of Community Facilities from the Perspective of the Elderly-Based on Walk Score Method. Urban Plan. Forum. 2017, 6, 45-53.

50. Wu, J.; Shen, N. Walk score method-based evaluation of social service function of urban park green lands in Futian district, Shenzhen, China. Acta Ecol. Sin. 2017, 37, 7483-7492. [CrossRef]

51. Zhou, Y.; Long, Y. Large-scale evaluation for street walkability: Methodological improvements and the empirical application in Chengdu. Shanghai Urban Plan. Rev. 2017, 1, 88-93.

52. Long, Y.; Zhao, J.; Li, S.; Zhou, Y.; Xu, L. The large-scale calculation of 'walk score' of main cities in China. New Archit. 2018, 1, 4-8.

53. Yingbin, L. The Walkability Measurement and the Validation Study of the Taoyuan District in Shenzhen. Ph.D. Thesis, Harbin Institute of Technology, Harbin, China, 2013.

54. Bereitschaft, B. Equity in neighbourhood walkability? A comparative analysis of three large U.S. cities. Local Environ. 2017, 22, 859-879. [CrossRef]

55. Bereitschaft, B. Equity in Microscale Urban Design and Walkability: A Photographic Survey of Six Pittsburgh Streetscapes. Sustainability 2017, 9, 1233. [CrossRef]

56. King, S.B.; Kaczynski, A.T.; Wilt, J.K.; Stowe, E.W. Walkability 101: A Multi-Method Assessment of the Walkability at a University Campus. SAGE Open 2020, 10, 2158244020917954. [CrossRef]

57. Li, X.; Maghelal, P.; Tso, Y.E.; Ryan, M.; Durodoye, J.; Wangpatravanich, P.; Jensen, K. Evaluating walkability and bikeability in a campus setting. PBEJ 2016, 5, 11-29.

58. Molina-García, J.; Castillo, I.; Sallis, J.F. Psychosocial and environmental correlates of active commuting for university students. Prev. Med. 2010, 51, 136-138. [CrossRef]

59. Peachey, A.A.; Baller, S.L. Perceived Built Environment Characteristics of On-Campus and Off-Campus Neighborhoods Associated with Physical Activity of College Students. J. Am. Coll. Health 2015, 63, 337-342. [CrossRef]

60. Reed, J.A.; Ainsworth, B. Perceptions of Environmental Supports on the Physical Activity Behaviors of University Men and Women: A Preliminary Investigation. J. Am. Coll. Health 2007, 56, 199-204. [CrossRef]

61. Reed, J.A.; Phillips, D.A. Relationships Between Physical Activity and the Proximity of Exercise Facilities and Home Exercise Equipment Used by Undergraduate University Students. J. Am. Coll. Health 2005, 53, 285-290. [CrossRef]

62. Roemmich, J.N.; Balantekin, K.N.; Beeler, J.E. Park-Like Campus Settings and Physical Activity. J. Am. Coll. Health 2014, 63, 68-72. [CrossRef]

63. Vale, D.S.; Pereira, M.; Viana, C.M. Different destination, different commuting pattern? Analyzing the influence of the campus location on commuting. J. Transp. Land Use 2018, 11, 1-18. [CrossRef]

64. Lu, Y.; Wang, D. Walkability measuring in America and its enlightenment. Urban Plan. Int. 2012, $27,10-15$.

65. Walk Score 2011. Walk Score Methodology. Available online: https://www.walkscore.com/methodology.shtml (accessed on 7 June 2011).

66. Ewing, R.; Schmid, T.; Killingsworth, R.; Zlot, A.; Raudenbush, S. Relationship between Urban Sprawl and Physical Activity, Obesity, and Morbidity. Am. J. Health Promot. 2003, 18, 47-57. [CrossRef] [PubMed]

67. Hajrasouliha, A.H. Master-planning the American campus: Goals, actions, and design strategies. Urban Des. Int. 2017, 22, 363-381. [CrossRef]

68. Lau, S.S.Y.; Gou, Z.; Liu, Y. Healthy campus by open space design: Approaches and guidelines. Front. Arch. Res. 2014, 3, 452-467. [CrossRef]

69. Hipp, J.A.; Gulwadi, G.B.; Alves, S.; Sequeira, S. The Relationship Between Perceived Greenness and Perceived Restorativeness of University Campuses and Student-Reported Quality of Life. Environ. Behav. 2016, 48, 1292-1308. [CrossRef]

70. Zhou, J. From better understandings to proactive actions: Housing location and commuting mode choices among university students. Transp. Policy 2014, 33, 166-175. [CrossRef] 
71. Slater, S.J.; Nicholson, L.; Chriqui, J.; Barker, D.C.; Chaloupka, F.J.; Johnston, L.D. Walkable communities and adolescent weight. Am. J. Prev. Med. 2013, 44, 164-168. [CrossRef]

72. Gordon-Larsen, P.; Hou, N.; Sidney, S.; Sternfeld, B.; Lewis, C.; Jacobs, D.R.; Popkin, B. Fifteen-year longitudinal trends in walking patterns and their impact on weight change. Am. J. Clin. Nutr. 2008, 89, 19-26. [CrossRef]

73. Sallis, J.F.; Hovell, M.F.; Hofstetter, C.R.; Elder, J.P.; Hackley, M.; Caspersen, C.J.; E Powell, K. Distance between homes and exercise facilities related to frequency of exercise among San Diego residents. Public Health Rep. 1990, 105, 179-185.

74. Reed, J.A. Perceptions of the Availability of Recreational Physical Activity Facilities on a University Campus. J. Am. Coll. Health 2007, 55, 189-194. [CrossRef]

75. King, A.C.; Jeffery, R.W.; Fridinger, F.; Dusenbury, L.; Provence, S.; Hedlund, S.A.; Spangler, K. Environmental and Policy Approaches to Cardiovascular Disease Prevention Through Physical Activity: Issues and Opportunities. Health Educ. Q. 1995, 22, 499-511. [CrossRef] [PubMed]

76. Koohsari, M.J.; Sugiyama, T.; Hanibuchi, T.; Shibata, A.; Ishii, K.; Liao, Y.; Oka, K. Validity of walk score®as a measure of neighborhood walkability in Japan. Prev. Med. Rep. 2018, 9, 114-117. [CrossRef] [PubMed]

77. Leslie, E.; Coffee, N.; Frank, L.; Owen, N.; Bauman, A.; Hugo, G. Walkability of local communities: Using geographic information systems to objectively assess relevant environmental attributes. Health Place 2007, 13, 111-122. [CrossRef] [PubMed]

78. Hajrasouliha, A. Connecting the Dots: Campus Form, Student Perceptions, and Academic Performance. Focus 2019, 15, 12.

79. Salingaros Nikos, A. Biophilia and Healing Environments; Terrapin Bright Green: New York, NY, USA, 2015.

80. Bopp, M.; Kaczynski, A.; Bs, P.W. Active Commuting Patterns at a Large, Midwestern College Campus. J. Am. Coll. Health 2011, 59, 605-611. [CrossRef]

81. Ewing, R.; Handy, S. Measuring the Unmeasurable: Urban Design Qualities Related to Walkability. J. Urban Des. 2009, 14, 65-84. [CrossRef]

82. Ewing, R.; Handy, S.; Brownson, R.C.; Clemente, O.; Winston, E. Identifying and Measuring Urban Design Qualities Related to Walkability. J. Phys. Act. Health 2006, 3, S223-S240. [CrossRef]

83. Ewing, R.; Clemente, O. Measuring Urban Design: Metrics for Livable Places; Island Press: Washington, DC, USA, 2013.

84. Ewing, R.; Hajrasouliha, A.; Neckerman, K.M.; Purciel-Hill, M.; Greene, W.H. Streetscape Features Related to Pedestrian Activity. J. Plan. Educ. Res. 2015, 36, 5-15. [CrossRef]

Publisher's Note: MDPI stays neutral with regard to jurisdictional claims in published maps and institutional affiliations.

(C) 2020 by the authors. Licensee MDPI, Basel, Switzerland. This article is an open access article distributed under the terms and conditions of the Creative Commons Attribution (CC BY) license (http://creativecommons.org/licenses/by/4.0/). 